\title{
Mulheres, homens, olhares e cenas na mira do gênero
}

\author{
Mulheres, homens, olhares e \\ cenas.
}

ADELMAN, Miriam et al. (Org).

Curitiba: UFPR, 2011.268 p.
A coletânea Mulheres, homens, olhares e cenas convida-nos a uma leitura pouco usual nos estudos sobre cinema e mídias contemporâneas, aqui entendidas como espaços privilegiados de produção de discursos e significados de gênero. Isso requer uma abordagem que ultrapasse as análises comumente feitas sobre cinema e feminismo e/ou estudos de gênero - que tem o seu valor na desconstrução das imagens do feminino e suas relações com o masculino na linguagem fílmica - em direção a uma proposta de análise discursiva sobre as mulheres, os homens e os múltiplos olhares e cenas nos quais eles e elas se movem.

A proposta desta coletânea está assentada em três questionamentos básicos: quais são os lugares institucionalizados de representação de mulheres, homens e "outros" nos filmes? Como incorporam as lutas e as formas de contestação dessas representações das últimas décadas? Como aparecem os "outros lugares" (marginais, contra-hegemônicos) e de que maneira são abordados?

As respostas a esses questionamentos são apresentadas nos 16 artigos subdivididos em cinco partes. Na primeira parte, intitulada "Gêneros brasileiros", três artigos discutem as representações de gênero no cinema brasileiro, passeando pelos temas do amor erótico, do casamento, da traição, da política e das eternas dicotomias do feminino e do masculino na produção nacional. Os filmes revisitados foram Dona Flor e seus dois maridos, lançado em 1976, cuja análise das autoras Amélia S. Corrêa e Ana Carolina R. Trovão dialoga com a cultura nacional, a produção do cinema brasileiro, a contextualização do movimento feminista na década de 1970 e as representações discursivas do romance de Jorge Amado sobre as idealizações masculinas a respeito das mulheres, ora vulgares e libertinas, ora frágeis e emotivas, mas sempre "mulheres" em relação aos "homens". O artigo "A dona da história: trajetória de Elizabeth em Cabra marcado para morrer", de Joana de C. Dorea e Sonia W. Maluf, conta a história do filme Cabra marcado para morrer a respeito do assassinato do líder camponês João Pedro Teixeira, da Paraíba, a mando dos latifundiários em 1962. O artigo destaca a fala da esposa desse líder, Elizabeth, em dois momentos.

Na primeira filmagem, sua fala fica enviesada pelo discurso da morte de seu marido, ela aparece apenas como a viúva do grande líder. Dezessete anos depois, na segunda filmagem, uma nova Elisabeth entra em cena e conduz o filme para o olhar e a fala da mulher, e não da viúva, exibindo nessa narrativa os fragmentos e as rupturas dos cabras e das "cabras" marcados para morrer... Os filmes mais recentes - Uma vida em segredo, Durval discos e O céu de Suely, produzidos em 2002 e 2006 - são analisados no último artigo dessa parte por Sandra Fischer a partir das discussões do feminino "reimagina(n)do", isto é, não o feminino na eterna luta com o masculino, mas $\circ$ feminino que se constrói, muitas vezes, pela ausência do masculino. A análise, cujo cenário principal nos três filmes é a família, pauta-se pelas relações sociais de gênero, pelos papéis e pelos lugares dicotomizados na relação mulher-homem e na diversidade discursiva que repousa sobre as figuras femininas.

A segunda parte, "Margens e fronteiras", traz quatro artigos que problematizam o universo da homossexualidade, ainda tão estigmatizado pelo determinismo biológico e pelas representações essencialistas da sexualidade, que confere aos homens o prazer sexual pelo instinto e às mulheres 
pelo amor romântico. Sabrina B. Lopes, no artigo intitulado "Minha vida em cor-de-rosa e o performativo", discute as contribuições dos conceitos "performativo" de Judith Butler e "performance" e "drama social" de Victor Turner para pensar o drama particular do pequeno Ludovic, que não se identifica com seu sexo biológico no filme Minha vida em cor-de-rosa, de 1997. Na sequência, dois artigos tematizam as relações de gênero no filme "O segredo de Brokeback Mountain", de 2005. Richard Miskolci discute no artigo "As vidas em segredo de Brokeback Mountain" os paradoxos que perpassam a receptividade e a repulsa do público diante dos temas tratados na relação homossexual dos protagonistas Ennis e Jack, especialmente o dilema do "armário" e o sonho do casamento. Já Benedito Costa Neto explora o conceito de "western gay" retratado nesse filme no artigo "Notas sobre Brokeback Mountain de Ang Lee", problematizando as teias discursivas que constroem os significados de "western" e "gay", especialmente aqueles construídos pela indústria cultural norte-americana a respeito desse filme e de outros, como, por exemplo, Capote, Café da manhã em Plutão e Transamérica, nos quais o tratamento e a classificação pejorativa e estereotipada dos sujeitos são analisados por Neto como reflexo das tensões que ainda cercam as representações do homossexualismo na linguagem cinematográfica.

Finalizando essa parte, o artigo de Carla Rodrigues, "A força da biologia: representações da sexualidade em Denys Arcand", analisa as representações da sexualidade nos filmes $O$ declínio do Império Americano, de 1986, e Invasões bárbaras, de 2003. Guiada pelas discussões do sociólogo Michel Bozon,' a autora discorre sobre as consequências das transformações da sexualidade no contexto social da chamada "revolução sexual" iniciada na década de 1960. Entretanto, mais uma vez aparece a "força da biologia", como diz a autora, impulsionando os discursos e as práticas de mulheres e homens presos em papéis e expectativas sociais claramente naturalizadores. Um exemplo é o discurso da liberdade sexual entremeado com a massificação da educação e a participação crescente das mulheres no mercado de trabalho de fins da década de 1980. Outro exemplo é a relativização do conceito de "revolução sexual" se consideradas as assimetrias e as desigualdades de gênero, classe e geração; afinal, certos comportamentos sexuais não são permitidos para certas mulheres e ainda diferem de acordo com sua classe e idade, conforme reitera Rodrigues ao finalizar o texto dizendo que "[...] nem a biologia é tão determinante nem é tão desprezível assim, nem todas as senhoras da terceira idade abriram mão do sexo, nem todos os homens da terceira idade são felizes com mulheres mais jovens" (p. 123).

Ficções científicas são o tema da terceira parte, que traz dois artigos. Luis Fernando Lopes Pereira analisa as "Ambiguidades perdidas no espaço: gênero e contracultura na ficção científica" e Ana Paula Vosne Martins discute "O martírio da tenente Ripley: a mulher e o mal no cinema de ficção científica". Pereira recupera a discussão sobre cultura de massa, televisão, psicodelia e contracultura na ficção científica da década de 1960, especialmente os anos finais dessa década, quando emergem as manifestações da contracultura e do feminismo. Indo além da crítica de Adorno e Horkheimer, principais representantes da Escola de Frankfurt, sobre a produção dos bens culturais e a massificação do capitalismo, Pereira segue o entendimento de Walter Benjamim a respeito da relação paradoxal entre a "perda da aura" e a popularização da arte no contexto de sua reprodutibilidade técnica e a noção metodológica de circularidade cultural dos historiadores Carlo Ginzburg ${ }^{2} \mathrm{e}$ Robert Darnton. ${ }^{3}$ No contexto das novas tecnologias, o autor discute as circularidades das culturas de elite e popular em relação às imagens do feminino e do masculino nos filmes Barbarella e O planeta dos macacos, e principalmente com o advento da televisão e das séries televisas como Perdidos no espaço e Jornada nas estrelas. Por seu turno, Ana Paula Martins discute as visões tradicionais do feminino na eterna luta entre o bem e o mal retratados no conjunto de filmes Alien. Com destaque na lendária heroína Helen Ripley, Martins analisa as diversas representações misóginas que essa personagem ganhou na saga, dialogando na fronteira do desejo e do mal que a figura feminina desperta no homem, ainda que presa em sua aparência misógina.

A penúltima parte da obra convida-nos a indagar sobre que mulher é essa, produzida nas tramas discursivas do cotidiano e do real embaralhados nas cenas e na estética da arte midiática. Denílson Lopes abre essa parte com o texto "Novos cotidianos, novas famílias", no qual discute as diversas interpretações teóricas da poética do cotidiano ${ }^{4} \mathrm{e}$ dos estudos culturais. ${ }^{5}$ Apoiado nas discussões de Maffesolli ${ }^{6}$ e $\mathrm{Heller}^{7}$ sobre o resgate do cotidiano, suas ambivalências e hierarquias não são mais pensadas como espaço de sociabilidade, mas sim como paisagem, como espaço de resistência e intimidade que podem ser percebidas nos dois 
filmes - Entre amigos e Colcha de retalhos, e também nas séries televisivas como Dawson's Creek. Anna Beatriz Paula discute as produções indianas e as representações de gênero no texto "Cinema popular indiano: o feminino interrompido", dando ênfase às versões bollywoodiana da mulher indiana.

Após um breve histórico sobre o cinema indiano, diferenciando as produções relacionadas à indústria cinematográfica de Bollywood e aquelas produzidas em condição diaspórica, dentro e fora dos territórios indianos, a autora discute as representações do feminino travestidas de uma roupagem moderna que mostra, de um lado, mulheres em confronto com as tradições milenares de sua cultura e, de outro, a sua reinserção às tradições movidas pelo amor a um homem que as reconcilia com o passado. Paula discute vários paradoxos do feminino, desde a mulher solteira símbolo da sedução, da mulher casada símbolo da tradição familiar, até a condição subalterna e estigmatizada das atrizes em meio a um cenário predominantemente masculino e a atuação de mulheres que ousam ser diretoras, no contexto do cinema diaspórico, como, por exemplo, Deepa Mehta em sua trilogia Earth, Fire, Water.

Ainda nesse bloco de discussões sobre a mulher, Maria Rita de Assis César abre seu texto sobre "Notas para um cinema da diferença: algumas imagens de mulheres em filmes recentes" com uma pergunta perturbadora: "Afinal, o que deseja uma mulher?". As respostas a essa pergunta aparentemente simples abrem uma avalanche de estereótipos, como o das mulheres insatisfeitas por "natureza", que são demasiadamente explorados pela mídia contemporânea. César discute as tradicionais dicotomias femininas trazidas pelo universo da mídia a respeito de certa produção da subjetividade feminina, como as imagens da rainha do lar/mãe devotada, presentes no imaginário midiático dos anos de 1950, e o seu inverso, a femme fatale e/ou a mulher neurótica, possessiva e assassina que povoa $\circ$ imaginário mais recente dos filmes de Hollywood. Como contraponto, a autora discute outras produções do chamado cinema da diferença, como os filmes The hours e Dolls.

O último artigo desse bloco, "De quem é esta buceta? Um comentário feminista", escrito por Bell Hooks e traduzido por Lennita Oliveira Ruggi, traz uma perspectiva feminista sobre o filme Ela quer tudo, de Spike Lee. O artigo apresenta como o debate feminista pode colaborar no questionamento dos estereótipos sobre a sexualidade de mulheres negras e a controvertida questão da mulher emancipada como sexualmente promíscua. Temas ligados à emancipação, à liberação sexual, à sexualidade feminina negra e ao desejo, à promiscuidade, à completude sexual e ao estupro articulam-se com as representações da sexualidade masculina sob a forma de manipulação e controle do desejo sexual por parte do homem. Em outras palavras, a pergunta "De quem é esta buceta?", feita para a protagonista do filme durante a cena do estupro, revela todas as tensões, dicotomias e estereótipos de gênero tecidos nas narrativas e nas ações masculinas, e não femininas, analisadas nesse artigo a fim de elucidar como velhas roupagens sexistas podem reaparecer e seduzir mesmo o mais atento espectador.

Após a discussão dos gêneros brasileiros, das margens e fronteiras, das ficções científicas e das diversas representações das mulheres na arte cinematográfica, o último bloco da obra, "Diretoras e escritoras", reúne três artigos. O primeiro, de Miriam Adelman e Lennita O. Ruggi, discute "Gênero, família e as marcas da violência em marcas do silêncio". O artigo explora as diferentes representações e os papéis de gênero e de classe do universo fílmico da escritora Dorothy Allison e da diretora Angélica Huston, cujos personagens evocam histórias e conflitos permeados de violência física e simbólica, de homens e mulheres de gerações diferentes. Para Adelman e Ruggi, esse filme situa-se fora das representações convencionais da mulher porque a própria diretora enquadra-se na corrente de literatura queer e sua contundente crítica à matriz heterossexual e/ou heteronormatividade, tal como discute Judith Butler. ${ }^{8}$

Essa parece ser a mesma conclusão dos dois últimos artigos, pois esses exploram o universo da heteronormatividade da cineasta Jane Campion, no artigo "Prazer em assistir: o cinema de Jane Campion", de Sue Guilett, traduzido por Amélia S. Correa e Lennita $O$. Ruggi, e da cineasta feminista Marleen Gorris, no artigo "Nem mulher, nem esposa, nem mãe: o filme $A$ excêntrica família de Antonia", de Vânia Sandeleia Vaz da Silva. O primeiro analisa a dimensão visual e narrativa dos filmes dirigidos por Jane Campion como Retrato de uma mulher, com Nicole Kidman e Bárbara Hershey, O Piano, com Holly Hunter, Um anjo em minha mesa, com Kerry Fox, e Fogo sagrado, com Kate Winslet, atrizes famosas que são retratadas por uma narrativa que não explora ou reafirma a beleza e a sensualidade que lhes são usualmente atribuídas, mas uma estética que propõe uma nova representação de feminilidade, de corpo 
feminino, que em nada remete à fantasiosa normatividade hollywoodiana do feminino. $O$ artigo abre com a discussão sobre o olhar que visualiza e representa as mulheres, depois avança na discussão da ação dos homens, cujo tema principal desenrola-se no âmbito da violência e da sexualidade do universo masculino, mas não sob a ótica do homem patriarcal dominador, e sim das possibilidades de seu desvelamento, ou seja, o objetivo da cineasta não é julgar ou punir os homens, mas, como mostra Sue Guilett, "decifrar sua luxúria destrutiva" (p. 233).

O último artigo discute os limites e as possibilidades do conceito de gênero para pensar o filme $A$ excêntrica família de Antonia, cuja proposta é a desconstrução das ideias de mulher, esposa, mãe e família, não necessariamente nessa ordem. O ponto de cruzamento das histórias das mulheres retratadas nesse filme e exploradas nesse artigo está no fato de todas elas terem rompido com alguns dos elementos que "definem" uma mulher, como, por exemplo, ser esposa de alguém, ter atitudes "femininas" ou ter um filho mas não se sentir mãe. Assim, o artigo explora as articulações de sexo/gênero, plasticidade e heteronormatividade a partir de autores como Rita Segatto, Jane Flax e Judith Butler. O artigo inicia-se com uma longa citação de André Comte-Sponville sobre o que é a doçura feminina e finaliza com uma intrigante comparação da personagem Antonia com a mulher virtuosa de Comte-Spponville e com a metafísica do amor de Arthur Schopenhauer.

Sendo assim, esta obra não é apenas uma coletânea de artigos sobre os discursos e significados de gênero e das imagens do feminino e masculino na linguagem fílmica, é um convite inquietante para uma nova postura diante dos outros lugares, cenas e olhares que invadem nossas mentes e corações pelas telas, das quais tantas vezes não saímos impunes.

\section{Notas}

${ }^{1}$ Michel BOZON, 2004.

${ }^{2}$ Carlo GINZBURG, 1987.

${ }^{3}$ Robert DARNTON, 1988.

${ }^{4}$ André BAZIN, 1987; e Michel de CERTEAU, 1998.

${ }^{5}$ Mario PERNIOLA, 2002; e Slavoj ZIZEK, 2003.

${ }^{6}$ Michel MAFFESOLLI, 1988.

${ }^{7}$ Agnes HELLER, 2000.

8 Judith BUTLER, 2007.

\section{Referências}

BAZIN, André. "Le réalisme cinématographique et l'Ecole Italienne de la libération". In: Qu'est-ce que le ciéma? Paris: Cerf, 1987.

BOZON, Michel. Sociologia da sexualidade. Rio de Janeiro: FGV, 2004.

BUTLER, Judith. Gender Trouble. New York: Routledge, 2007.

CERTEAU, Michel de. A invenção do cotidiano. Petrópolis: Vozes, 1998. v. 1/2.

DARNTON, Robert. Boemia literária e revolução. São Paulo: Cia das Letras, 1988.

GINZBURG, Carlo. O queijo e os vermes: o cotidiano de um moleiro perseguido pela Inquisição. São Paulo: Cia das Letras, 1987.

HELLER, Agnes. O cotidiano e a história. São Paulo: Paz e Terra, 2000.

MAFFESOLLI, Michel. O conhecimento comum. São Paulo: Brasiliense, 1988.

PERNIOLA, Mario. El arte y su sombra. Madrid: Cátedra, 2002.

ZIZEK, Slavoj. Bem-vindo ao Deserto do Real. São Paulo: Boitempo, 2003.

Ana Claudia Delfini Capistrano de Oliveira Universidade do Vale do Itajaí 